\title{
Evidence to end FGM/C: Research to help girls and women thrive
}

Population Council

Follow this and additional works at: https://knowledgecommons.popcouncil.org/departments_sbsr-rh

Part of the Demography, Population, and Ecology Commons, Family, Life Course, and Society Commons, International Public Health Commons, Maternal and Child Health Commons, Sociology of Culture Commons, and the Women's Health Commons How does access to this work benefit you? Let us know!

\section{Recommended Citation}

"Evidence to end FGM/C: Research to help girls and women thrive," fact sheet. Washington, DC: Population Council, 2016. 


\section{FACT}

SHEET

APRIL 2016

Lead Institution

Population Council

Key Partners

Africa Coordination

Centre for

Abandonment of

Female Genital

Mutilation/Cutting,

Kenya

Gender and

Reproductive Health

\& Rights Resource

Centre, Sudan

Global Research and

Advocacy Group,

Senegal

MannionDaniels Ltd.

Population

Reference Bureau

University of

Washington (Prof.

Bettina Shell-Duncan)

University of

California, San Diego

(Dr. Gerry Mackie)

Funded by

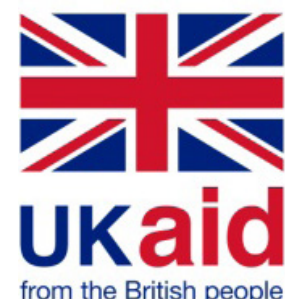

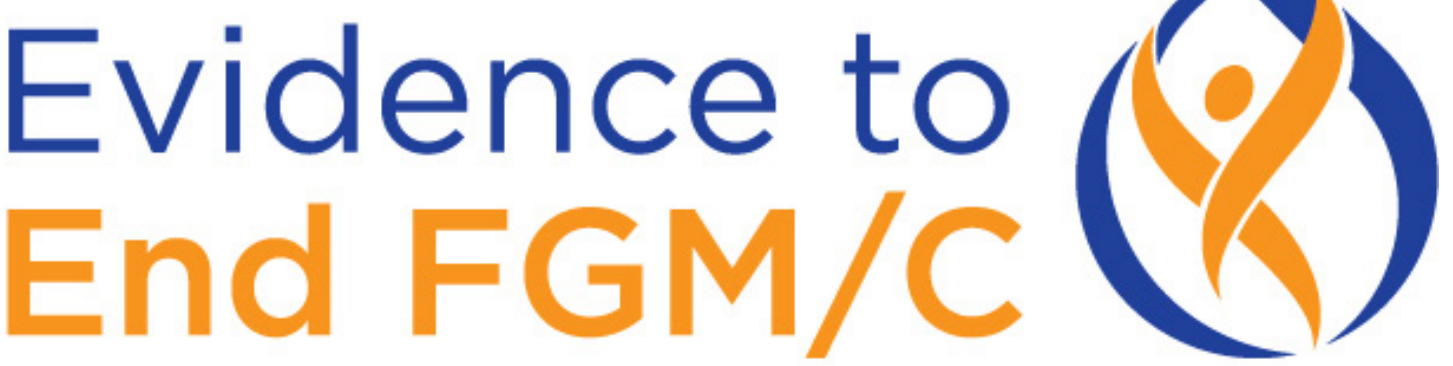

Research to Help Girls and Women Thrive

A new Population

Council-led research

programme, funded

by the United

Kingdom's Department

for International

Development (DFID), will join the UNFPA-

UNICEF Joint

Programme on FGM/C:

Accelerating Change and the Girl Generation

in the Campaign to

End Female Genital

Mutilation/Cutting

(FGM/C) within One

Generation.

\section{BACKGROUND}

$\mathrm{FGM} / \mathrm{C}$ is a harmful practice involving cutting, removing,

and sometimes sewing up external female genitalia for nonmedical reasons. More than 130 million girls and women have undergone FGM/C in 29 of the highest prevalence countries where it is practiced today, and 30 million girls under the age of 15 are at risk over the next decade. Yet we need much more evidence on the best strategies for ending $\mathrm{FGM} / \mathrm{C}$, including:

- knowledge of the drivers and consequences of FGM/C in specific contexts, to build a detailed understanding that also enables generalizations;

- the impacts of FGM/C interventions, which requires strengthened monitoring and evaluation frameworks and systems;

- increased work on research methods for strengthening available data;

- more attention given to theory-based intervention and evaluation designs; and

- improved coordination efforts ensuring greater research utilisation for meaningful policy and programme changes. 
Resolutions by the UN Commission on the Status of Women in 2010, the African Union and European Union in 2011-12, and most importantly the 2012 UN General Assembly have all called for intensified global efforts to end FGM/C within one generation.

\section{THE RESPONSE}

The FGM/C Research Programme will generate highquality evidence to influence strategic investment, policy and programming to end FGM/C. This fiveyear programme will work in 6-9 sub-Saharan African countries to dramatically expand the body of evidence on the most effective approaches to ending FGM/C. The research programme will be organized around four themes:

- Building the picture of where, when, and why FG$\mathrm{M} / \mathrm{C}$ is practiced through a series of explanatory analyses of existing survey datasets and qualitative studies among various populations at different stages of abandoning the practice.

- Assessing a range of programmed interventions around FGM/C abandonment that utilize a blend of retrospective evaluations, case studies of ongoing interventions, prospective implementation research, impact evaluations and cost analyses. Multi-site implementation studies will help generalize findings.

- Understanding the wider impacts of $F G M / C$ on the lives of girls, women, and their families, and the implications of abandoning the practice-as well as other harmful practices such as early marriage and gender-based violence-on gender norms and relations.

- Improving research into FGM/C by addressing the challenges of ethically and accurately measuring prevalence and FGM/C status; improving designs to evaluate complex interventions commonly used for FGM/C abandonment; enhancing the application of theory of change to research on FGM/C abandonment; improving definition and measurement of social norms and norms changes; and increasing the rigor, relevance and utility of scientific descriptions of FGM/C interventions and their evaluation.

\section{THE APPROACH}

An African led research consortium that will work alongside other programmes in a global campaign to end $\mathrm{FGM} / \mathrm{C}$. The consortium is guided by 3 principles: do no harm, get behind and support an African-led movement to end $\mathrm{FGM} / \mathrm{C}$, and understand $\mathrm{FGM} / \mathrm{C}$ within the wider context of violence and discrimination against women.

The research programme will simultaneously implement five inter-related elements to ensure the evidence base will influence strategic investment, policies and programmes to end FGM/C. We will:

- Engage stakeholders continuously and use tailored strategies that recognise the differences in types of decisions and evidence needs, communications channels, and capacity to use research-based evidence.

- Generate high-quality evidence through appropriately designed research, rigorously and ethically implemented.

- Work with stakeholders to determine the decisions for which they need evidence, for example: investment, policy, or programming decisions, and the appropriate communications mechanisms to reach them.

- Conduct capacity-building activities to ensure researchers have the necessary orientation and skills to undertake research to the highest quality and ethical standards, competencies to translate research findings and ability to provide firm recommendations to inform decision-making by national and global stakeholders.

- Regularly monitor and evaluate activities that include stakeholder engagement, generation of high quality evidence and its communication, and capacity building to ensure achievement of the FGM/C programme's targets.

This programme will advance the ambitious goal of ending $\mathrm{FGM} / \mathrm{C}$ within a generation and reducing the practice by 30 percent in at least 10 countries over the next 5 years.

Please address any inquiries about the Evidence to end FGM/C research programme to the Project Director, Dr. Jacinta Muteshi: jmuteshi@popcouncil.org.
The Population Council conducts research and delivers solutions that improve lives around the world. Big ideas supported by evidence: It's our model for global change. popcouncil.org

(C) 2015 The Population Council, Inc.
POPULATION COUNCIL

Ideas. Evidence. Impact. 